emotional atmosphere which existed when "The Origin of Species" was published. This is followed by the story of how evolutionary theory gathered momentum and support with the re-discovery of the Mendelian laws of heredity. The latter part of the book explores the significance of genetics in human life and development. In general, the historical and factual part of Hardin's book is remarkably good, mainly because of the interesting and often novel anecdotes and reminiscences which the author produces to support the theories and philosophies of the leading personalia.

When Hardin begins to speculate, however, he adopts the overbearing attitude so typical of those who see the world devoid of any shade of grey. Darwin is chided for his lack of mathematics, his support of pangenesis, and his inability "to discover genetics". All Lamarkists are banished from court. "Samuel Butler and St. George Mivart were intensely proud and personally ambitious far beyond their small abilities". It would be interesting to hear Hardin's assessment of a well-known English professor of zoology who advocates that more may be heard of the inheritance of acquired characteristics when the possibilities of cytoplasmic inheritance have been further explored. In his attack on the Soviet attitude to genetics - which is weakened when Hardin adopts the approach of a journalist rather than a man of science-Needham, Bornal and Haldane are accused of something almost verging on intellectual dishonesty. All this to support Hardin's strongly held view that what evolutionary theory and genetic laws have taught us is the essential need for competition if human life is to go on.

It is a pity that the author has spoilt what might have beon a good book with over-protestation. "Nature and Man's Fate" should bring him much publicity but little credit.

T. H. Hawkins

\section{HEAT TRANSFER AND HEAT EXCHANGERS}

\section{Heat Transfer}

Vol. 2. By the late Max Jakob. With the technical and editorial assistance of Prof. S. P. Kezios. Pp. xxxii +652. (New York: John Wiley and Sons, Inc.; London: Chapman and Hall, Ltd., 1957.) 120s, net.

An Introduction to Fluid Mechanics and Heat Transfer

With Applications in Chemical and Mechanical Process Engineering. By Prof. J. M. Kay. Pp. xvi 309. (Cambridge: At the University Press, 1957.) 37s. $6 d$.

\section{Heat Exchangers}

Applications to Gas Turbines. By Dr. W. Hryniszak. Pp. xii + 343. (London: Butterworths Scientific Publications; New York: Academic Press, Inc., 1958.) $63 s$. ; 10 dollars.

7 'HE second volume of the late Prof. M. Jakob's treatise on "Heat Transfer", completed under the guidance of his colleague, Prof. S. P. Kezios, maintains the very high standard set by the first. The first volume left over for consideration the solution of the equations for radiant heat transfer in non-absorbing and absorbing media, a topic which occupies the first quarter of this second volume.
The greater part of the book deals with selected fields of application in heat-transfer engineering, discussing first the well-established topics by giving a mathematical treatment of recuperative and regenerative heat exchangers and cooling tower theory. There follows consideration of the newer branches of study in the science of heat transfer, including transpiration cooling and cooling by falling liquid films, heat transfer problems encountered at high fluid velocity through laminar and turbulent boundary layers, and concluding with chapters on heat transfer in liquid metals and in packed columns. A supplement brings up to date some of the material in Volume 1, though none of the many literature references given throughout the book is carried beyond 1953, and indeed those relating to regenerator theory do not go beyond 1940. Presentation of further material is held over to a later edition of the treatise. The two volumes together form an indispensable work of reference for the libraries of all heat transfer laboratories.

Prof. Kay's book is based directly on a university course of lectures in chemical engineering. Picking up this book after Prof. Jackob's two volumes, one wonders how the author has compressed into a modest volume an introduction both to heat transfer and fluid mechanics. This has been achieved by an admirably concise mathematical treatment of his material, but also by omitting entirely consideration of radiant heat transfer and any solution of the unsteady state conduction equations. The particular strength of the book lies in the successful manner in which it inter-relates and interweaves the phenomena of fluid flow, mass transfer and heat transfer. The author makes use of vector notation to an extent which need not cause undue difficulty to one to whom it is unfamiliar, though it seems inappropriate to introduce the simple concept of thermal resistance via equations written in vector notation. While there are a few short chapters at the end of the book dealing very briefly with applications in process engineering, the absence of any worthwhile mention of two-phase flow problems is surprising in a book written for chemical engineers. One suspects that this is because their study lends itself less readily to the neat and tidy mathematical treatment which features so largely in this book.

The book by Dr. Hryniszak is in a different category from the two others. While Prof. Jakob's is likely to appeal most to the postgraduate student and research worker and Prof. Kay's to the more able undergraduate, Dr. Hryniszak's would make little appeal to either, for it is essentially a book for the specialist in gas-turbine heat exchangers. Although the non-specialist student might find some interest in the sections dealing with the mechanical aspects of recuperative and regenerative heat exchangers, he would find little attraction in the manner of presentation of the theoretical matter; for in an attempt to keep the mathematics as simple as possible, the theoretical relations are frequently presented as complicated formulæ with little in the way of derivation. Consequently, the contents of the book too often resemble extracts from a design manual, and such manuals seldom make exciting reading. Only the specialist will have the patience and inclination to dig deeper if he wants to compare the author's methods with his own. The volume deals not only with the heat exchanger but also, in optimization procedures, treats it as an integral part of the gas-turbine $\begin{array}{ll}\text { plant. } & \text { R. W. HAYwOOD }\end{array}$ 